\title{
Improved design criterion for frictionally engaged contacts in overrunning clutches
}

\author{
Nadine Nagler ${ }^{1}$ D $\cdot$ Armin Lohrengel ${ }^{1}$ \\ Received: 23 February 2020 / Accepted: 27 May 2021 / Published online: 28 June 2021 \\ (c) The Author(s) 2021
}

\begin{abstract}
Overrunning clutches, also known as freewheel clutches, are frictionally engaged, directional clutches; they transmit torque depending on the Freewheel clutch rings' rotation directions. The torque causes a tangential force in the Hertzian contact area. The hitherto "state-of-the-art design criterion" bases on this load situation. In practice, axial loads additionally act on the frictionally engaged Hertzian contact area. This additional axial load can cause the loss of the friction connection and so the freewheel clutch slips. This publication presents an improved design criterion for frictionally engaged contacts in freewheel clutches. It allows to consider tangential as well as axial loads during the design process. Additionally, it offers the possibility to estimate the probability of frictional engagement loss and gross slip based on the freewheel clutch's application scenario. This publication points out how to use the improved design criterion to design freewheel clutches that are more robust against a loss of function.
\end{abstract}

\section{Erweitertes Auslegungskriterium für reibschlüssige Kontakte in Freilaufkupplungen}

\section{Zusammenfassung}

Freilaufkupplungen sind reibschlüssig und richtungsabhängig wirkende Kupplungen. Sie übertragen Torsionsmomente abhängig von den Rotationsrichtungen der Antriebs- und Abtriebsseite zueinander. Das Torsionsmoment verursacht mit dem entsprechenden Hebelarm eine Tangentialkraft im Bereich der Hertz'schen Kontaktfläche. Für dieses Lastszenario existiert eine Auslegungsvorschrift. In der Praxis treten im Hertz'schen Kontaktbereich zusätzlich Axialkräfte auf. Bei sonst unveränderten Beanspruchungsrandbedingungen können diese zusätzlichen Axialkräfte zum Verlust des Reibschlusses und damit zum Funktionsverlust der Freilaufkupplung führen. Diese Veröffentlichung stellt eine verbesserte Auslegungsvorschrift für reibschlüssig wirkende Freilaufkupplungen vor. Die erweiterte Auslegungsvorschrift gestattet die Berücksichtigung der kombinierten Beanspruchung aus Axial- und Radialkräften im Hertz'schen Kontaktbereich bei der Auslegung von Freilaufkupplungen. Sie ermöglicht die Abschätzung der Wahrscheinlichkeit eines Funktionsverlusts durch die Aufhebung des Reibschlusses in den Hertz'schen Kontakten. Diese Veröffentlichung demonstriert, wie die Nutzung der erweiterten Auslegungsvorschrift zur Gestaltung funktionssichererer Freilaufkupplungen beiträgt.

\section{Abbreviations \\ i Counting variable \\ j Counting variable \\ z Number of clamping elements}

Nadine Nagler

nadine.nagler.pub@falaba.de

Armin Lohrengel

lohrengel@imw.tu-clausthal.de

1 Institute of Mechanical Engineering, Robert-Koch-Str. 32, 38678 Clausthal-Zellerfeld, Germany

$\begin{array}{ll}\alpha & \text { (rad) Clamping angle } \\ \alpha_{0} & \text { (rad) Clamping angle at initial position } \\ \alpha_{i} & \text { (rad) Clamping angle at current position } \\ \mu & \text { Friction coefficient } \\ \mu_{\text {req }} & \text { Required friction coefficient } \\ F_{i} & \text { (N) Force at inner ring } \\ F_{o} & \text { (N) Force at outer ring } \\ F_{t} & \text { (N) Tangential force } \\ F_{t, i} & \text { (N) Tangential force at inner ring } \\ F_{t, o} & \text { (N) Tangential force at outer ring } \\ F_{n} & \text { (N) Normal force } \\ F_{n, i} & \text { (N) Normal force at inner ring }\end{array}$


$\mathrm{F}_{\mathrm{n}, \mathrm{o}} \quad$ (N) Normal force at inner ring

$\mathrm{F}_{\mathrm{ax}} \quad$ (N) Axial force

$\mathrm{F}_{\text {res }} \quad$ (N) Resulting force

$\mathrm{T} \quad(\mathrm{Nm})$ Torque

$\mathrm{T}_{\mathrm{i}} \quad(\mathrm{Nm})$ Trque at inner ring

$\mathrm{T}_{\mathrm{o}} \quad$ (Nm) Torque at outer ring

$\pi \quad$ Mathematical constant

$\rho \quad$ (rad) Opening angle of the friction cone

$\rho \quad\left(\mathrm{kg} / \mathrm{m}^{3}\right)$ Density

f $\quad(\mathrm{Hz})$ Frequency

$\varphi \quad$ (rad) Torsion angle

$v \quad$ Poisson ratio

$\mathrm{X} \quad$ (m) Clamping ramp height

s (m) Displacement distance due to relative rotation between the inner and the outer ring

$\mathrm{u}_{\mathrm{RO}, \mathrm{IR}}$ (m) Total deformation in roller to inner ring contact

$\mathrm{u}_{\mathrm{RO}, \mathrm{OR}}(\mathrm{m})$ Total deformation in roller to outer ring contact

$\mathrm{f}_{\mathrm{RO}, \mathrm{IR}} \quad(\mathrm{m})$ Deformation in roller to inner ring contact

$\mathrm{f}_{\mathrm{RO}, \mathrm{OR}} \quad(\mathrm{m})$ Deformation in roller to outer ring contact

d (m) Diameter

$\mathrm{r}_{\mathrm{IR}} \quad(\mathrm{m})$ Radius inner ring

$\mathrm{r}_{\mathrm{OR}} \quad(\mathrm{m})$ Radius outer ring

$\mathrm{r}_{\mathrm{RO}} \quad(\mathrm{m})$ Radius rolling element

\section{Introduction}

Freewheel clutches are frictionally engaged clutches with a long history of usage $[1,2]$. Depending on the application, freewheel clutches are available as sprag clutches, overrunning clutches, or retaining clutches. They all share the working principle of being connected by friction. Freewheel clutches are designed to transmit torque; the torque leads to tangential and radial forces in the contacts between the rollers and the rings. In contrast to rolling bearings, freewheel clutches are not designed to transmit axial loads, which exist in most technical applications. Therefore, rolling bearings often accompany freewheel clutches and handle the additional axial loads. Without the support of the rolling bearings, the freewheel clutch can lose its friction connection due to slippage and, with that, its ability to transmit torque.

This publication focuses on overrunning clutches and their application in drive trains. Degrees of non-uniformity cause other components like gears, belt systems, synchronizer rings, and rolling bearings to vibrate within the production-related axial clearance range. The overrunning clutch faces unwanted, additional axial loads that provoke a loss of friction connection in the Hertzian contact area. Sliding friction occurs and so the overrunning clutch loses its function abruptly. The hitherto valid design criterion [1] is

$\tan (\alpha)=\frac{F_{t}}{F_{n}} \leq \mu$

If this criterion is fulfilled, the friction connection in the Hertzian contact area is guaranteed. It states that the tangent of the clamping angle $\alpha$ must be smaller than the Hertzian contact zone's friction coefficient $\mu$. The clamping angle $\alpha$ in turn is equal to the quotient of the tangential force $F_{t}$, which results from the circumferential torque $\mathrm{T}$, and the normal force $F_{n}$, which acts in radial direction.

The design criterion (Eq. 1) does not take axial loads into account. Thus, it does not meet the load requirements of today's drive train applications. This publication presents an improved design criterion. The hitherto valid design criterion (Eq. 1) is the basis of the improved design criterion but corrected using current experimental research. Overrunning clutches are presented as an application example. The improved design criterion bases on physical principles; therefore, it is of interest for other Hertzian contact based friction connections.

\section{Working principle of overrunning clutches}

Fig. 1 shows the components of overrunning clutches and the forces that act within an overrunning clutch based on the contact of one roller, the rings, and the spring. Fig. 2 illustrates the two main operation modes-freewheeling and locking. The operation mode depends on the angular velocity differences and the moving direction of the clutch's components. The overrunning clutch operates in locking mode if

- the outer ring moves counterclockwise (ccw.) with a higher angular velocity than the inner ring;

- the inner ring moves clockwise (cw.) with a higher angular velocity than the outer ring.

The roller is clamped in the narrowed gap between the inner and outer ring, creating a frictional connection between the rings. The overrunning clutch transmits torque. It freewheels if

- the outer ring moves clockwise (cw.) with a higher angular velocity than the inner ring;

- the inner ring moves counterclockwise (ccw.) with a higher angular velocity than the outer ring.

The overrunning clutch does not transmit torque if it operates in freewheeling mode. In this operation mode the roller is in contact with the spring and rotates freely otherwise. The spring's task is to push the roller into the nar- 
Fig. 1 a Equilibrium of forces at Hertzian contact level, $\mathbf{b}$ friction cone [3] a

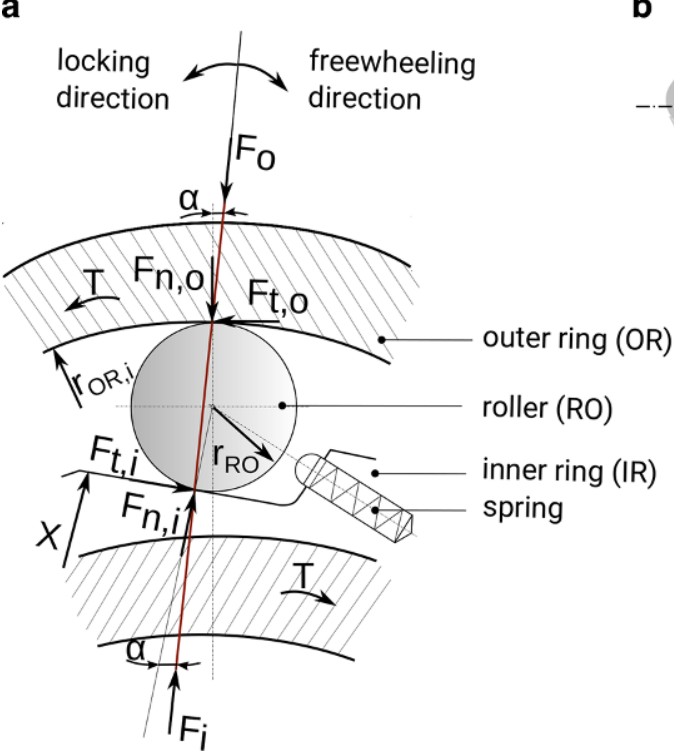

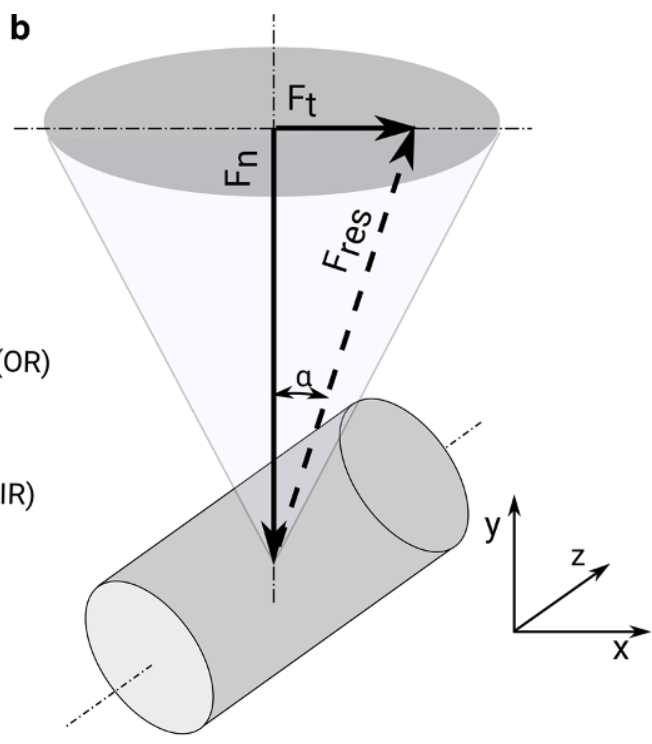

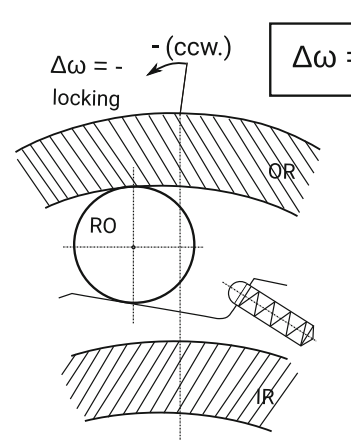

- OR moves ccW. \& $\omega_{\mathrm{OR}}>\omega_{\mathrm{IR}}$

- IR moves cW. \& $\omega_{\mathrm{OR}}<\omega_{\mathrm{IR}}$

Fig. 2 Freewheel clutch operation modes

rowing gap and thus shorten the needed time to change the operation mode from freewheel clutching to locking.

\section{Freewheel clutch design-state of the art}

Amongst others, [1, 3-10] and [11] discuss different aspects of overrunning clutch and freewheel clutch design. Each of these publications focuses on a specific design aspect.

All publications share the common understanding of the underlying basic physical principle, i.e. the friction connection in the Hertzian contact area. For example, [12-18, 20] and [21] discuss topics like contact mechanics, friction, stick-slip, and surface design that are not specific to freewheel clutches but relevant for freewheel clutch design.

This publication does not focus on the mathematical design approach of an appropriate friction connection. The above-mentioned publications provide this knowledge. It aims at the general understanding of the chosen approach

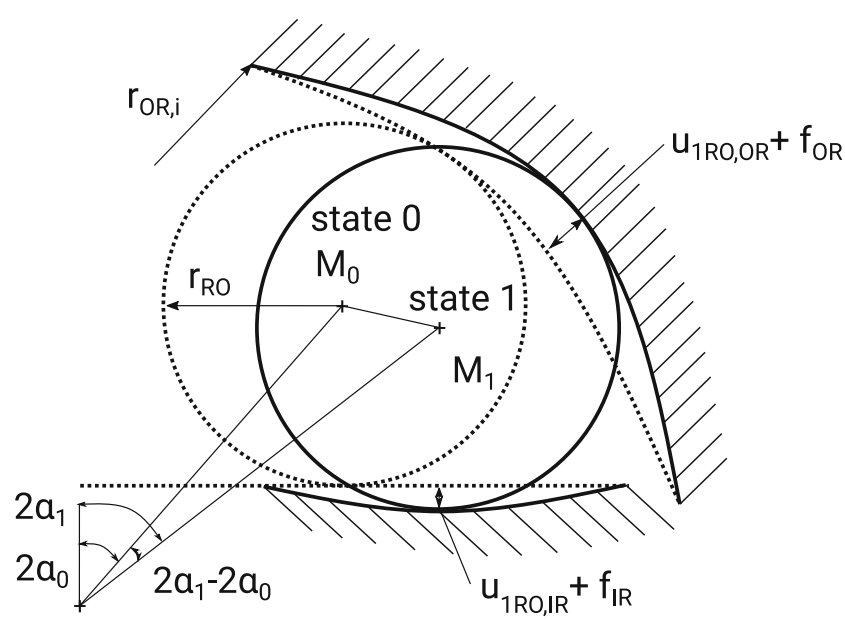

Fig. 3 Clamping angle change during operation [8]

to develop an improved freewheel clutch design criterion. Therefore, the design equations are presented in a way that is simplified accordingly. Fig. 1 shows the equilibrium of forces at the Hertzian inner and outer ring contacts. This means that:

$F_{t}=F_{t, i}=F_{t, o} \cdot F_{n}=F_{n, i}=F_{n, o} \cdot \alpha_{t, i}=\alpha_{t, o}$

Taking all $\mathrm{z}$ rollers into consideration leads to a transmittable torque of:

$T=T_{i}=T_{o}=z \cdot X \cdot F_{t, i}=z \cdot r_{O R, i} \cdot F_{t, o}$

One of the most important freewheel clutch design parameters is the clamping angle $\alpha$, which is composed of two parts: The freewheel clutch's assumed rigid contact geometry and the elastic load-/deformation relation. 
Fig. 4 Iterative calculation of load behavior [8]

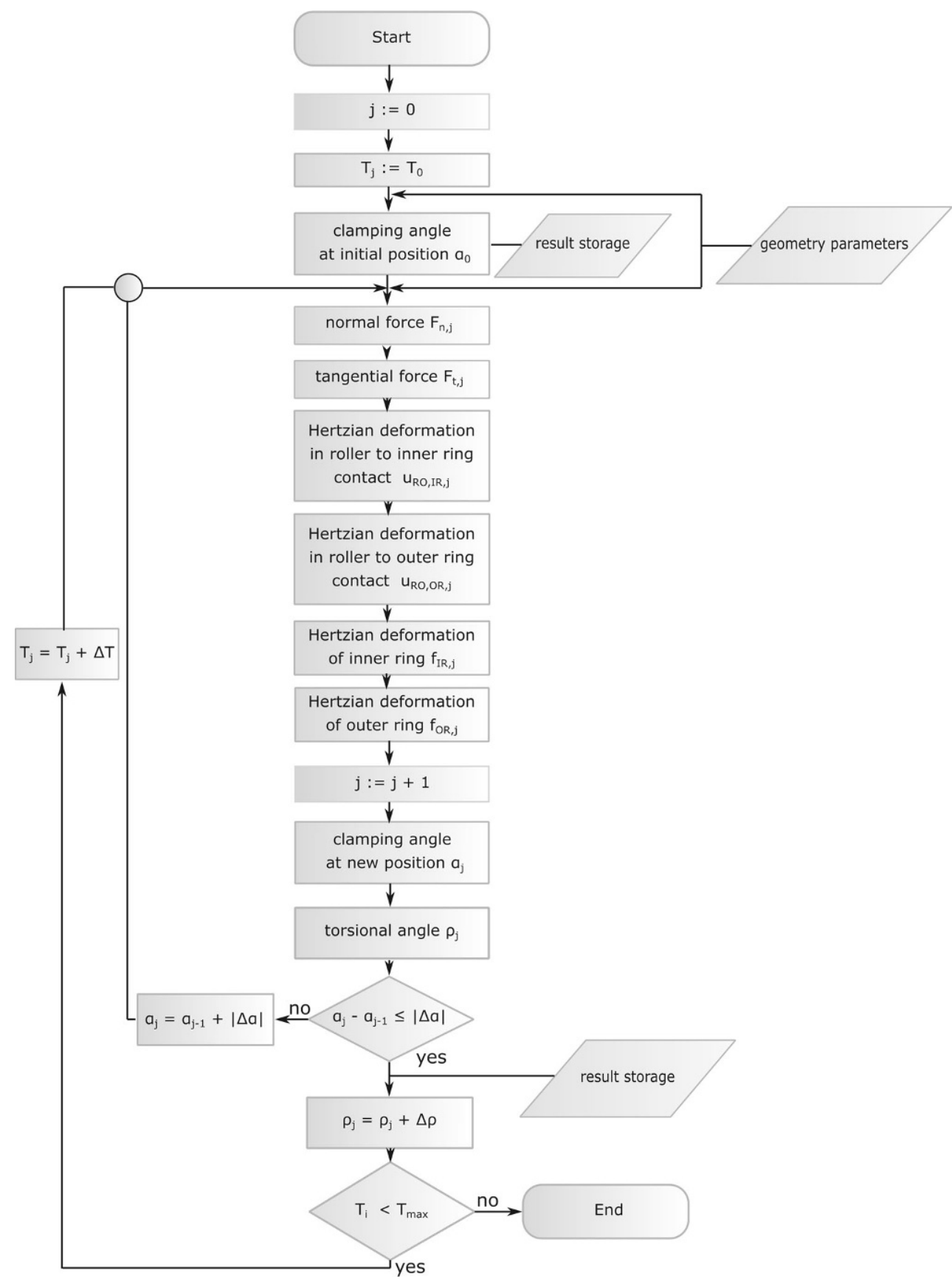

The solely geometry-based part suffices as a design approximation. It does not include forces that are derived from the initiated torque and is given by

$\cos (\alpha)=\cos \left(\alpha_{0}\right)=\sqrt{\frac{r_{\mathrm{RO}}+X}{2 \cdot\left(r_{\mathrm{OR}, \mathrm{i}}-r_{\mathrm{RO}}\right)}}$,

where $\alpha_{0}$ is the clamping angle at the initial position (Fig. 3).

The Freewheel clutch material is not rigid but elastic. Thus, the overall deformation is the sum of
- the forces that occur in locking mode and cause a deformation of the contacting components (inner ring, outer ring, and rollers);

- the stiffness of the shaft and the hub;

- the Hertzian contact pressure at the inner and outer ring contacts, which causes a flattening of the contacting surfaces.

With increasing loads, the roller moves further into the narrowing gap that appears to expand, Fig. 3. Starting at the initial position 0 , the roller's centre moves with a dis- 
tance s. The clamping angle at position 1 can be calculated according to Eq. 5, and the resulting distance s as shown in Eq. 6:

$$
\begin{aligned}
& \alpha_{1}=\frac{1}{2} \cos ^{-1}\left(\frac{X-f_{\mathrm{RO}, \mathrm{IR}}-u_{\mathrm{RO}, \mathrm{IR}}+r_{\mathrm{RO}}}{r_{\mathrm{OR}}-f_{\mathrm{RO}, \mathrm{OR}}-u_{\mathrm{RO}, \mathrm{OR}}+r_{\mathrm{RO}}}\right) \\
& s=\left(r_{\mathrm{OR}}+f_{\mathrm{RO}, \mathrm{OR}}+u_{\mathrm{RO}, \mathrm{OR}}-r_{\mathrm{RO}}\right) \cdot\left(2 \cdot \alpha_{1}-2 \cdot \alpha_{01}\right)
\end{aligned}
$$

Depending on the torque, the inner ring twists relatively to the outer ring with a torsion angle $\varphi$ [8]. The dependency between the torque and the angle $\varphi$ is the Freewheel clutch's torsional spring characteristic. The angle $\varphi$ can be measured or calculated (Eq. 7); it acts as an evaluation parameter for the test rig validation in Sect. 6.

$\varphi=\frac{s}{r_{\mathrm{OR}}}+\frac{s}{X}$

The geometric portion of the clamping angle $\alpha$ causes loads in the clamping contact. That, in turn, influences the elastic load-/deformation relation contribution to $\alpha$. This interdependence causes the necessity to calculate the freewheel clutch's load behavior iteratively (i.e. Newton-Raphson approach), Fig. 4.

\section{Research background, methodology and approach}

Sect. 1 introduces overrunning clutches, their applications in drivetrains, and the requirements they need to meet. Axial loads add to the forces that originate from the transmitted torque. Sect. 2 describes the state of the art of overrunning clutch design. A result is that the current design criterion given in Eq. 1 does not take axial loads in the overrunning clutch design into consideration. Thus, in order to achieve a reliable design of frictionally engaged freewheel clutches, the existing design criterion needs to be refined based on (Eq. 1) and the information presented in Sect. 2.

Accordingly, Sect. 4 discusses the derivation of an improved design criterion based on an analytical approach and on experiments with a newly developed dedicated test rig.

Sect. 5 provides information about the test rig, its design concept, the measurement concept, the test series boundary conditions, the validation of the test rig suitability, and measurement results. Sect. 6 deals with the validation of the improved design criterion by cross-checking it against experimental evidence from Sect. 5.

\section{Derivation of an improved design criterion}

If Eq. 1 is fulfilled, the friction connection at the Hertzian contacts is intact and the freewheel clutch transmits torque.
Fig. 1 illustrates the hitherto valid design criterion (Eq. 1) graphically. It indicates that this criterion is only valid for a two-dimensional load case and not for three-dimensional load cases which are caused by the additional axial load.

Based on the state of the art, the improved design criterion uses

- all three dimensions of the friction cone

- the friction coefficient $\mu$ in the Hertzian contact as a design criterion.

The numerator of Eq. 1 is expanded to

$\tan (\alpha)=\frac{\sqrt{F_{t}^{2}+F_{\mathrm{ax}}^{2}}}{F_{n}} \leq \mu$

Including Eq. 3 and rearranging Eq. 1 to get the normal force $F_{n}$ leads to

$\sqrt{\left(\frac{F_{\mathrm{ax}}^{2} \cdot r_{\mathrm{OR}, i}^{2}}{T^{2}}+1\right) \cdot \tan (\alpha)^{2}}<\mu$

Or, in short

$\mu_{\text {req }}<\mu$

It states that each load case requires an adequately amounted friction coefficient $\mu_{\text {req }}$ to be able to transmit torque without failure due to slippage. $\mu_{\text {req }}$ depends on the applied loads, the contact geometry, the design of the clamping angle $\alpha$ and material properties, amongst other parameters. In Eq. 10 the currently available friction coefficient $\mu$ is the counterpart to the required friction coefficient $\mu_{\text {req. }}$.

The improved design criterion states that the freewheel clutch transmits torque, based on frictional engagement, if the currently available friction coefficient $\mu$ is greater than the required friction coefficient $\mu_{\text {req }}$ that the load case demands. $\mu$ can be measured or estimated by literature review. Regarding the friction cone illustration (Fig. 1) it means that if the resulting force remains within the friction cone, the friction connection is guaranteed. As soon as the resulting force exceeds the friction cone, the inequality Eq. 10 is no longer fulfilled. The friction connection in the Hertzian contacts is lost, the freewheel clutch slips.

\section{Experimental investigations}

The improved design criterion is based on experimental investigations. Fig. 5 presents a photograph of the specially designed freewheel clutch test rig, while Fig. 6 shows a cross section of the test rig that contains the freewheel clutch. The objective of the rig was to investigate the 
Fig. 5 Photograph of freewheel clutch test rig
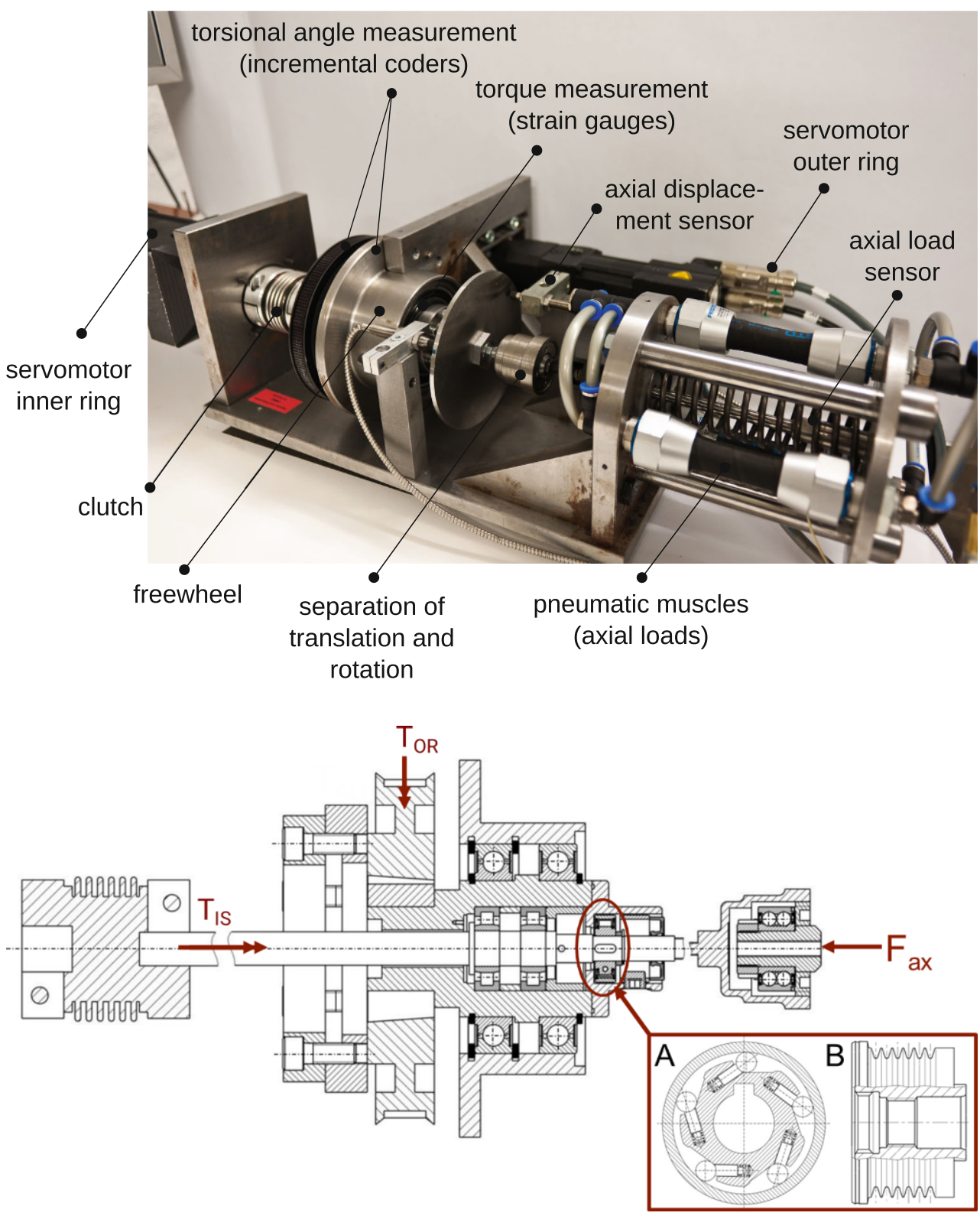

Fig. 6 Cross section of freewheel clutch test rig [3] dynamic behavior and lifetime performance of freewheel clutches by performing test series with different combinations of static and dynamic loads.

The installed measurement equipment allows to measure the axial load and displacement, the torque near the freewheel clutch's inner ring as well as at the servo motors, and the torsion angles at the inner and outer ring.

The realized concept is the result of a systematic design approach. At first, the basic requirements were established:

- definition of test specimen (freewheel clutch A and B)

- axial and radial load application

- load cases that include varying combinations of static and dynamic loads (Fig. 7)

- maximum test frequency for dynamic load cases $(30 \mathrm{~Hz})$
- maximum axial load $(3 \mathrm{kN})$

- maximum torque $(26 \mathrm{Nm})$

- maximum axial displacement at freewheel clutch inner ring (3 mm) switching component (inner ring)

- axial load application to component (inner ring)

- maximum torsion angle $\varphi\left( \pm 10^{\circ}\right)$

- measured parameters (torque, axial load, axial distance, torsion angle at the inner as well as the outer ring)

Most relevant were the decisions about how to apply and synchronize the loads and how to develop a control loop. In case of the axial load application, several working principles were investigated: pneumatic muscles, hydraulic actuators, piezo-electric actuators and shakers. Ultimately, pneumatic muscles were identified as the best choice to 

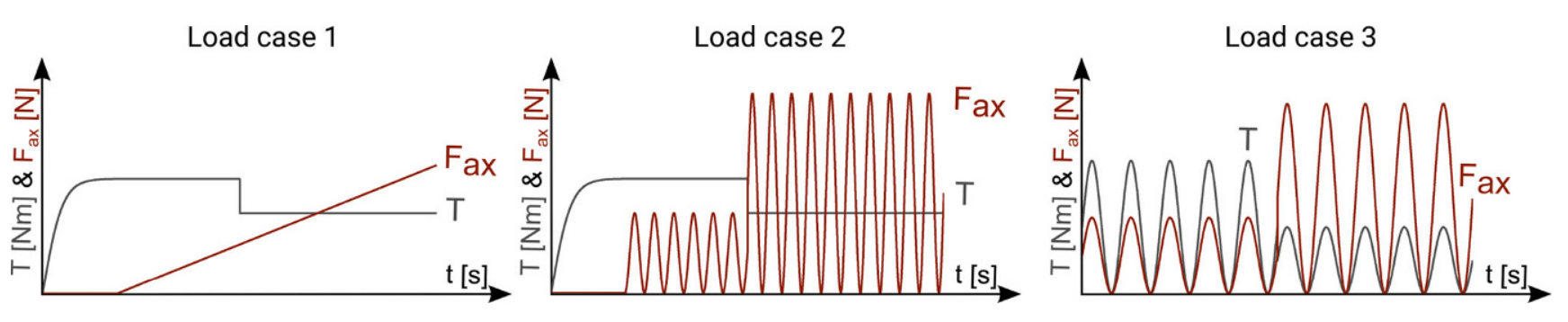

Fig. 7 Load cases [3]

Fig. 8 Test rig validation based on freewheel clutch A's torsion angle $\varphi[3]$

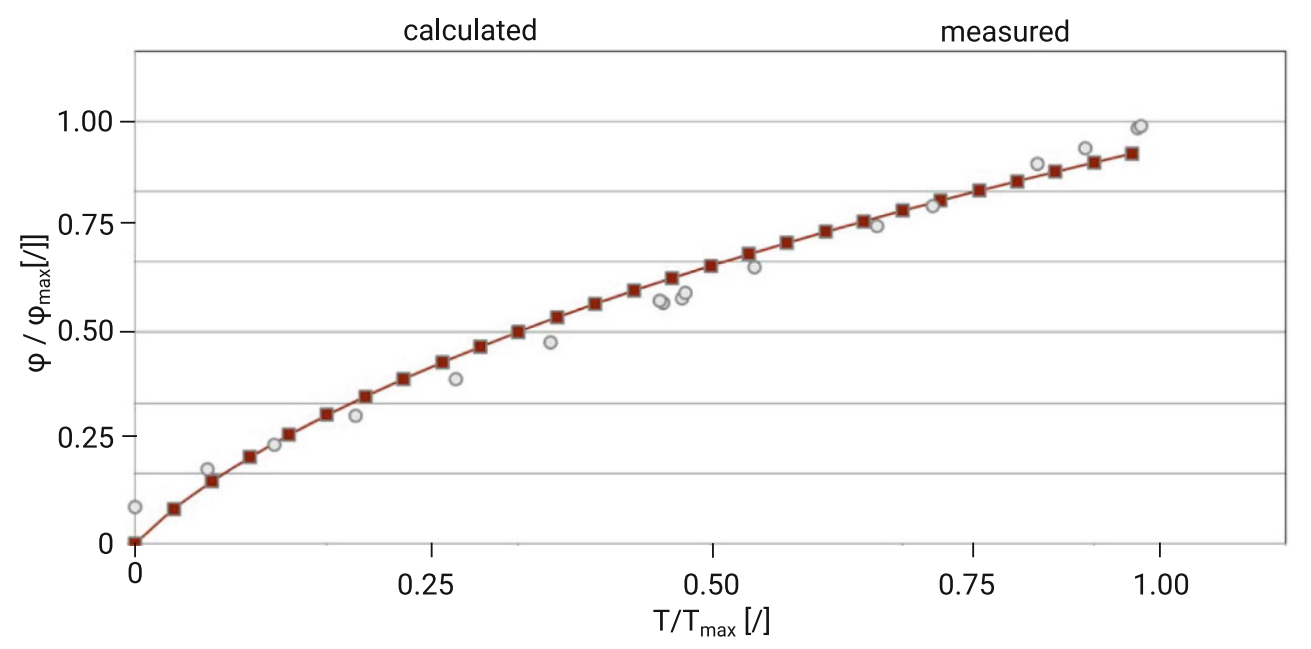

fulfill the competing requirements of acceptable costs and sufficient magnitude and frequency of axial loads and displacements, the more, as a compressed-air system was readily available with little effort. In terms of the torque application, the requirements restricted the possible options to hydraulic rotary actuators, torque motors and servomotors.

Hydraulic rotary actuators turned out not to reach the required frequencies. As torque motors were rejected due to their high costs and excessive space requirements, servomotors remained as the best solution. A control loop was created that included the pneumatic muscles as well as both servomotors and the measurement equipment. The synchronization of the control loop posed a challenge as it had to be particularly precise to be able to perform the required load cases (Fig. 7).

The capabilities of the test rig were validated by measuring the torsion angles $\varphi$ and comparing them with computational predictions (i.e. following the approach in Fig. 4), resulting in a close match, Fig. 8. Fig. 7 and Table 1 summarize the load cases as well as the test series boundary conditions:

- load case one: both loads are stationary. Torque is applied first. After reaching its set point it is kept constant. Afterwards, axial load is applied and increased continuously.

- load case two: the torque is stationary and the axial load is alternating. The procedure resembles that of load case one. The frequency of the axial load modulation is kept constant whereas the amplitude is increased continuously.

- load case three: both loads are transient and applied simultaneously. Their modulation frequencies are identical. The torque amplitude is kept constant whereas the axial load amplitude is increased continuously.

The test runs are terminated when the friction connection is lost, indicated by gross slip of the freewheel clutches. It is recognizable in the measured data as a sudden torque reduction. At this point the design criterion according to Eq. 1 is not fulfilled anymore. A full factorial test design was chosen to ensure an unbiased interpretation of the resulting data. The overall number of test runs amounts to 500 per investigated freewheel clutch (Table 1).

FVA2 reference oil was chosen as lubricant, a mineral, paraffin solvent refined oil that does not contain additives. This excludes the potential additive influence on the freewheel clutch's slip behavior. Table 2 lists FVA2's characteristic properties. Fig. 9 summarizes the test results of load case 1 with freewheel clutch A.

The results show that the freewheel clutch can endure some amount of additional stationary axial load without losing the friction connection due to gross sliding. The freewheel clutch slips at a certain threshold value of further increased axial load. This behavior was observed at all 
Table 1 Test series boundary conditions [3]

\begin{tabular}{llllll}
\hline $\begin{array}{l}\text { Load } \\
\text { case }\end{array}$ & $\begin{array}{l}\text { Freewheel } \\
\text { clutch }\end{array}$ & $\begin{array}{l}\text { Torque } \\
T[\mathrm{Nm}]\end{array}$ & $\begin{array}{l}\text { Axial load } \\
\text { Amplitude } \\
F_{a x}[\mathrm{~N}]\end{array}$ & $\begin{array}{l}\text { Axial load } \\
\text { Frequency } \\
f[\mathrm{~Hz}]\end{array}$ & $\begin{array}{c}\text { Lubricant } \\
\text { Number of } \\
\text { tests }\end{array}$ \\
\hline 1 & A \& B & $1,2, \ldots, 26$ & $0,200, \ldots, 3000$ & 0 & 41 \\
2 & A & $1,2, \ldots, 26$ & $0,200, \ldots, 3000$ & $1,2, \ldots, 5$ & FVA2 \\
3 & A \& B & $1,2, \ldots, 26$ & $0,500, \ldots, 3000$ & $1,2, \ldots, 5$ & FVA2 \\
\hline
\end{tabular}

Table 2 Lubricant properties of FVA2 reference oil [19]

\begin{tabular}{lll}
\hline Property & Unit & Value \\
\hline Density $\varrho$ at $15^{\circ} \mathrm{C}$ & $\mathrm{kg} / \mathrm{m}^{3}$ & 878 \\
Kinematic viscosity $\boldsymbol{v}$ at $40^{\circ} \mathrm{C}$ & $\mathrm{mm}^{2} / \mathrm{s}$ & 31 \\
Kinematic viscosity $\boldsymbol{v}$ at $100^{\circ} \mathrm{C}$ & $\mathrm{mm}^{2} / \mathrm{s}$ & 5.35 \\
ISO VG class & {$[/]$} & 32 \\
Pour point & ${ }^{\circ} \mathrm{C}$ & $\leq$ \\
Flash point & ${ }^{\circ} \mathrm{C}$ & 224 \\
\hline
\end{tabular}

test runs, regardless of the load case or tested freewheel clutch (A, B). There was a clear distinction between nonslipping and slipping freewheel clutch operating conditions. This observation served as a basis for the development of the improved design criterion that allows to include superimposed axial loads.

\section{Validation of improved design criterion by cross-checking against experimental evidence}

Applying the improved design criterion to the test rig results (Fig. 9) leads to Fig. 10. It demonstrates that three categories exist that describe the frictional engagement status in the Hertzian contacts and thereby the freewheel clutch's failure probability due to slippage. At an average of

- $\frac{\mu}{\mu_{\text {req }}}<0.8$, freewheel clutch A most likely loses the friction connection

- $0.8 \leq \frac{\mu}{\mu_{\text {req }}}<1.0$, freewheel clutch A partially loses the friction connection

- $\frac{\mu}{\mu_{\text {req }}} \geq 1.0$, freewheel clutch A very rarely loses the friction connection.

These observations lead to an abstracted "traffic light" slippage prediction model that is based on the improved design criterion (Eq. 10):

- Green symbolizes the condition in which the freewheel clutch functions reliably with low risk of failure due to slippage.

- Yellow symbolizes the condition in which a function loss due to slippage is unlikely, yet not impossible.

- Red symbolizes the condition in which the freewheel clutch will certainly lose its function due to slippage.
This model visualizes the improved design criterion. It enables the freewheel clutch designer and user to estimate the freewheel clutch's failure probability due to slippage. A prove for its applicability to other freewheel clutches is presented in Fig. 11, by the example of freewheel type B. Fig. 12 shows that freewheel clutch B's slippage behavior resembles the one of freewheel clutch A. The improved design criterion and its visualization in the form of the traffic light model are, within the investigated dimensions, usable for other freewheel clutches too. As the improved design criterion bases on a physical operating principle, it may be applicable to other Hertzian friction connections too.

\section{Conclusion}

Freewheel clutches are frictionally engaged, directional clutches. A loss of the friction connection on contact level due to gross slip is equivalent to a function loss of the freewheel clutch. The hitherto valid design criterion included the forces that result from the applied torque $T$. It was not possible to consider additional static or dynamic axial loads as well. This publication presents an improved design criterion that allows a function loss prognosis including axial loads.

At first, the improved design criterion was derived analytically, based on the state of the art freewheel clutch design criterion (Sect. 2). To prove its validity experimentally, a dedicated test rig was built (Sect. 3) and employed for an appropriately designed set of measurements which demonstrated its proper functioning. Subsequently, a full factorial test plan was carried out with two test specimens (freewheel clutch A and B). The improved design criterion was applied and found to be suitable for both test specimen; thereby, its validity was clearly confirmed (Sect. 6).

Funding The underlying project was funded as IGF-Vorhaben 17083 N/1 by the Industrielle Gemeinschaftsforschung of the Bundesministerium für Wirtschaft und Energie, Germany

Funding Open Access funding enabled and organized by Projekt DEAL.

Conflict of interest N. Nagler and A. Lohrengel declare that they have no competing interests. 
Fig. 9 Freewheel clutch A, load case 1 , result overview [3]

Fig. 10 Freewheel clutch A, load case 1 , application of improved design criterion [3]
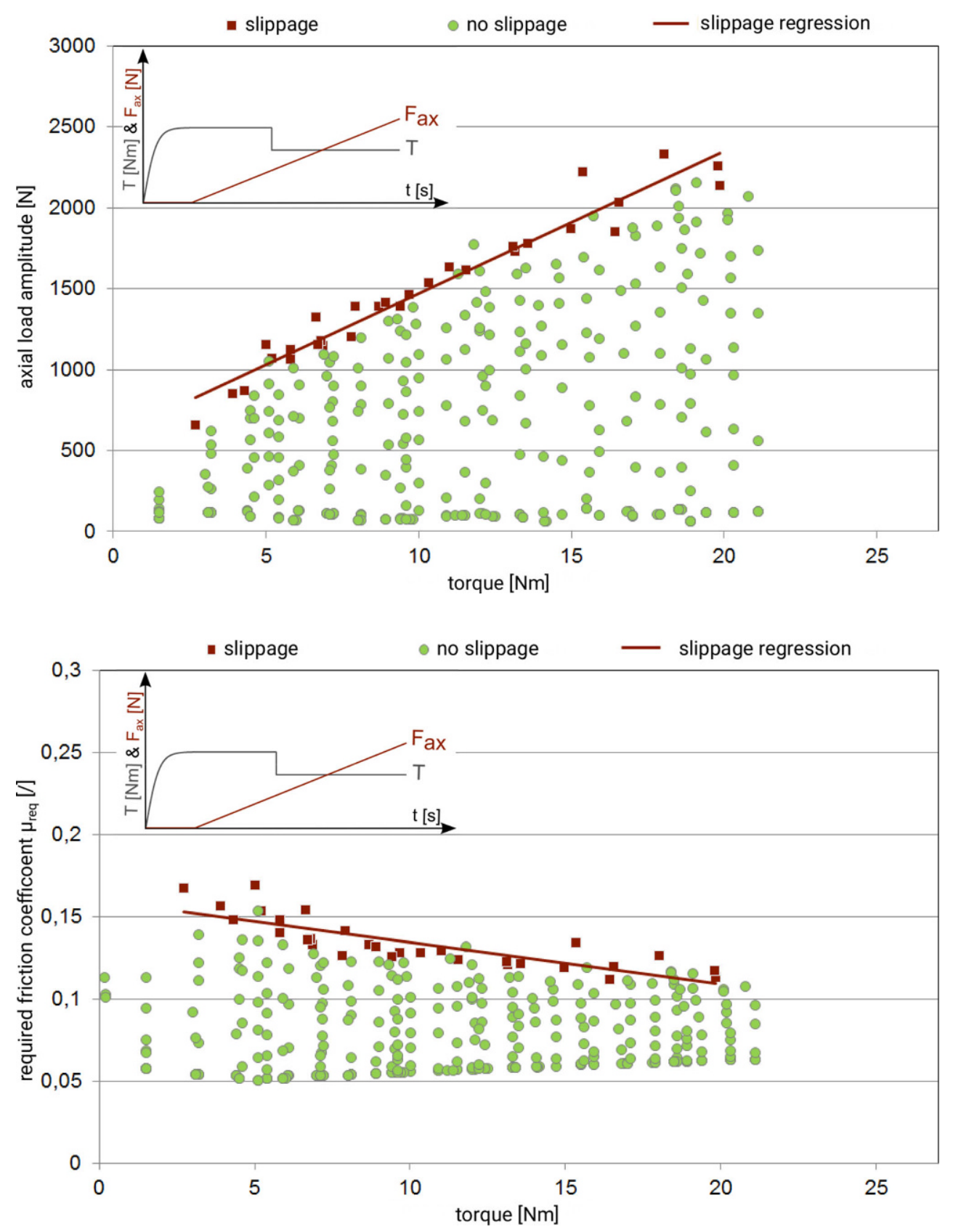
Fig. 11 Freewheel clutch A \& B, load case 1 , observed slippage due to friction loss [3]

Fig. 12 Freewheel clutch B, load case 1 , application of improved design criterion [3]
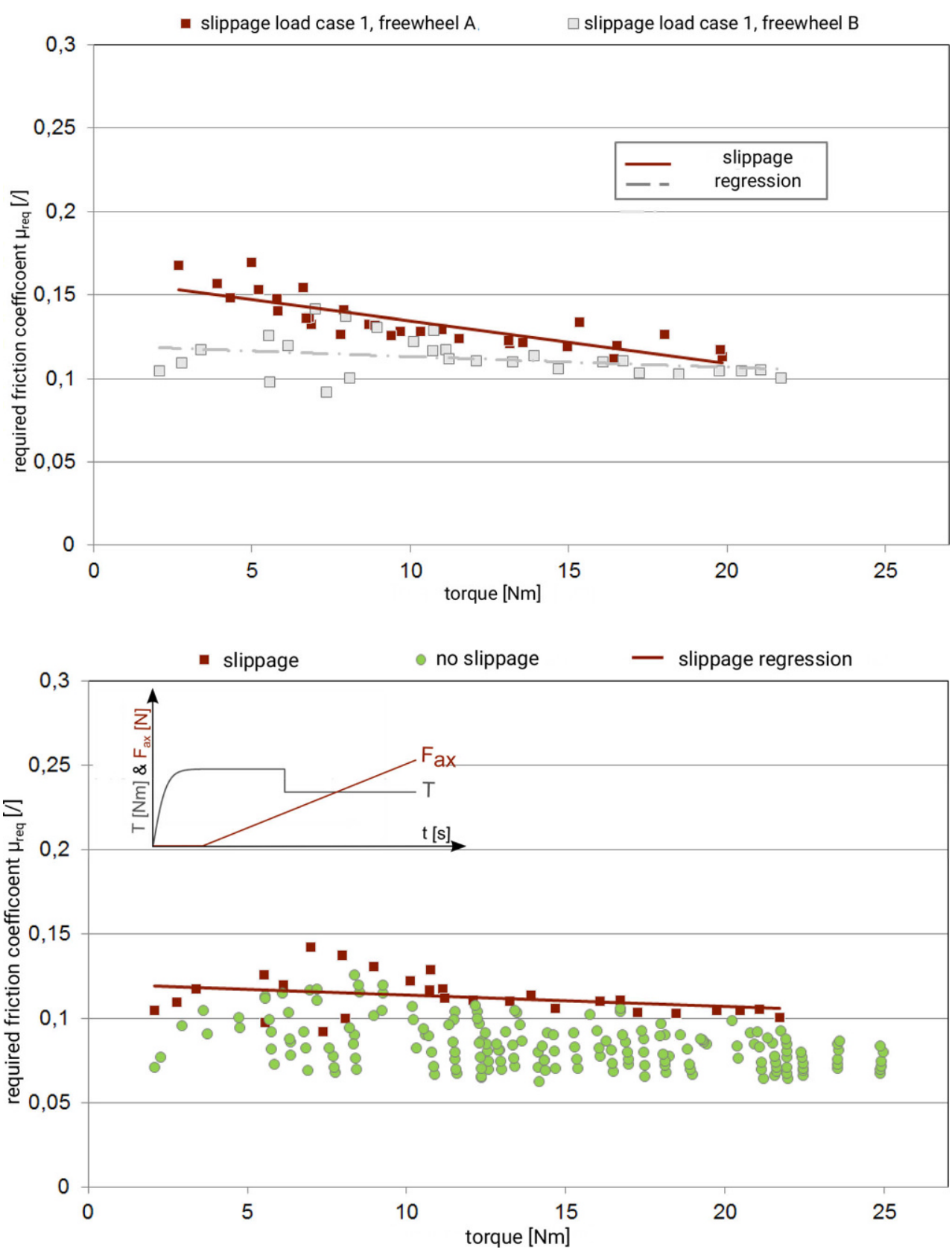

Open Access This article is licensed under a Creative Commons Attribution 4.0 International License, which permits use, sharing, adaptation, distribution and reproduction in any medium or format, as long as you give appropriate credit to the original author(s) and the source, provide a link to the Creative Commons licence, and indicate if changes were made. The images or other third party material in this article are included in the article's Creative Commons licence, unless indicated otherwise in a credit line to the material. If material is not included in the article's Creative Commons licence and your intended use is not permitted by statutory regulation or exceeds the permitted use, you will need to obtain permission directly from the copyright holder. To view a copy of this licence, visit http://creativecommons.org/licenses/by/4. $0 /$.

\section{References}

1. Stölzle K, Hart S (1961) Freilaufkupplungen, Berechnung und Konstruktion, 1st edn. vol 19. Springer, Berlin, Heidelberg

2. Grote K, Feldhusen J (2011) Dubbel: Taschenbuch für den Maschinenbau, 23rd edn. Springer, Berlin, Heidelberg, New York

3. Nagler N (2016) Einfluss einer zusätzlichen Axiallast auf das Übertragungsverhalten von Klemmrollenfreiläufen. PhD Thesis, Technische Universität Clausthal, Germany

4. Liu K, Bamba E (1998) Frictional dynamics of the overrunning clutch for pulse-continuously variable speed transmissions: rolling friction. Wear 217:208-214. https://doi.org/10.1016/S00431648(98)00176-8 
5. Liu K, Bamba E (2005) Analytical model of sliding friction in an overrunning clutch. Tribol Int 38:187-194. https://doi.org/10.1016/ S0301-679X(03)00033-1

6. Liu Y, Lin Z (2019) Simulation and experimental research on dynamic characteristics of overrunning clutch. J Vibroeng 21:570-586

7. Lohrengel A (1999) Lebensdauer von Klemmkörperfreiläufen im dynamischen Schaltbetrieb. FVA-Forschungsheftheft, vol 552. Forschungsvereinigung Antriebstechnik e.V. (VDMA), Frankfurt a.M.

8. Lohrengel A (2001) Lebensdauerorientierte Dimensionierung von Klemmrollenfreiläufen. $\mathrm{PhD}$ Thesis, RWTH Aachen University, Germany

9. Welter R (1990) Lebensdauer von Klemmkörperfreiläufen im Schaltbetrieb. FVA-Forschungsheft, vol 319. Forschungsvereinigung Antriebstechnik e. V. (VDMA), Frankfurt a.M.

10. Deppenkemper P, Lohrengel A (1999) Lebensdauer von Klemmkörperfreiläufen im Schaltbetrieb. FVA-Forschungsheft, vol 551. Forschungsvereinigung Antriebstechnik e.V. (VDMA), Frankfurt a.M.

11. Hüllenkremer M (2009) Ringbeanspruchung, JFRED 2.4. FVAForschungsheft, vol 891. Forschungsvereinigung Antriebstechnik e. V. (VDMA), Frankfurt a.M.

12. Bazrafshan M, de Rooij MB (2018) On the role of adhesion and roughness in stick-slip transition at the contact of two bodies: a numerical study. Tribol Int 121:381-388. https://doi.org/10.1016/j. triboint.2018.02.004

13. Barber JR (2018) Contact mechanics, 1st edn. Springer, Ann Arbor

14. Vermeulen PJ, Johnson KL (1964) Contact of nonspherical elastic bodies transmitting tangential forces. J Appl Mech 31(2):338-340. https://doi.org/10.1115/1.3629610

15. Tripp JH (1985) Hertzian contact in two and three dimensions. NASA technical paper, vol 2473

16. Sjö A (1996) Numerical aspects in contact mechanics and rolling bearing simulation. PhD Thesis, Lund University, Sweden

17. Courtney-Pratt JS, Eisner E (1957) The effect of a tangential force on the contact of metallic bodies. Proc R Soc A. https://doi.org/10. 1098/rspa.1957.0016

18. Johnson KL (1985) Contact mechanics, 1st edn. Cambridge University Press, Cambridge

19. Laukotka E (2007) Referenzölkatalog. FVA-Forschungsheft, vol 660. Forschungsvereinigung Antriebstechnik e. V. (VDMA), Frankfurt a.M.

20. Huang C (2018) Analytical modelling and optimization of logarithmic Sprag clutch considering profile modification. J Shock Vib. https://doi.org/10.1007/s10010-021-00496-5

21. Hofmann S (2019) Eine Theorie der behinderten radialen Aufweitung am stirnseitig befestigten Freilauf. PhD Thesis, Technische Universität Clausthal, Germany 